P. ROBERT-JAN SIMONS \& MANON C.P. RUIJTERS

LEARNING PROFESSIONALS: TOWARDS AN INTEGRATED MODEL

\begin{abstract}
In this chapter, we present a three-stage model of professional learning. It is based on practical experiences with professionals in a master program on the management of learning and development, consultancy practice, and research. We are motivated by our desire to gain an insight into the complexity and richness of learning of professionals. We expect that it will broaden our views on both learning and professionalism, and will help professionals and their organisations to accelerate their development.

First, we will define professionals and learning professionals. Next, we will consider the three ways of learning one by one: elaboration, expansion, and externalisation. We will then look briefly into the emotional motives behind and the consequences of the forms of professional learning. Finally, we will extend these ideas about individual learning towards collective forms of learning. Our ideas on collective learning have been described more fully elsewhere (Simons \& Ruijters, 2001). At several places in the chapter, we will present hypotheses about these ways of learning and their interrelations.
\end{abstract}

\title{
WHAT IS A LEARNING PROFESSIONAL?
}

\section{First thoughts on professionalism}

In order to give a definition of a learning professional, we should of course also define what professionals are and what learning is. The definition of a professional relates closely to professions and professional associations. Professions are mostly defined as domains of work that have an explicit body of knowledge described in handbooks and official (scientific) journals, have standards of quality, and professional associations (Thijssen, 1987). Professional associations bring these people together, define the standards of quality, help to develop the body of knowledge, and certify the education and training that will guarantee the quality of the learning outcomes.

Then, what is a professional? Are you a professional? Why or why not? Perhaps it is easier to explain what a professional is not. A professional is not a recognised member of a self-protective association of professionals defining standards of professionalism in terms of levels and kinds of education and training the person involved has completed. Thus, in our opinion, the physician who has done his medical training and has been

T.H.E. Editor(s) (ed.), Book title, 1-6.

(C) yyyy Kluwer Academic Publishers. Printed in the Netherlands. 
accepted as a member of the professional association of physicians is not yet a professional. We identify with the Dutch educationalist Lievegoed (cited in Germans, 1990), who already in the nineteen forties defined a professional in terms of vision, methodology, and tools and techniques. In our view, a real professional should meet the following criteria:

- Have an explicit vision about the profession and its contribution to society

- Have developed a unique methodology (way of working)

- Be able to work with a set of tools and techniques that fulfil quality criteria of the professional association mentioned before

- Demonstrate alignment between the vision, methodology, and tools and techniques.

A professional can now be defined as someone working in a professional field having an aligned combination of an explicit vision, a unique methodology, and a set of high quality tools and techniques. In our experiences in working with professionals, we have discovered that many "official" professionals do not meet these criteria. Few are even aware of their total body of knowledge or their vision, and alignment is not very often a criterion in the decision to embrace or reject specific tools or methodology. Perhaps, the very existence of the professional bodies mentioned before inhibit them from developing these ideas. They probably have the implicit idea that their education has equipped them with a complete and aligned package of professionalism. And perhaps this strong belief (we encounter this too often) that learning and professionalism result from following training courses, keep people from becoming professionals in the sense described above.

\section{From professional to learning professional}

Bodies of knowledge as well as standards of quality are changing rapidly. Training was not enough to become a professional in the past, and it will certainly not be so in the future. In our view, the concept of a professional as developed thus far is too static. Let us look into this a little more closely. Increasingly, we realise that tacit knowledge and skills developed while working cannot be trained easily, because they originate in the daily working with clients. Tacit knowledge and skills are therefore being revalued. It has become clear that knowledge and skills have a social life of their own (Brown \& Duguid, 2000): they originate in and can be distributed only in social interactions. This leads to a new emphasis on the need for collective learning.

Furthermore, we notice that the boundaries between the professions are fading. New developments emerge at the boundaries of disciplines, professions, and perspectives (Engeström, 1999). Multiperspective learning is needed between communities of practice as much as within community learning (Lehtinen, 2001). Finally, innovation is an important characteristic of 
present-day work. The question is how professionals can contribute to the innovation of their professions. For all these reasons, we need a more dynamic concept of the professional. We have called this the "learning professional".

It is again Lievegoed (1977) who shows us the way. Already a long time ago, he wrote that there are three main activities to be performed: to be working in practice, to be connected with or carrying out research, and to be teaching others. (1) One can only be and remain a professional when working in practice with clients. For a physician this means 'working with patients', for a manager 'working with employees', and for a researcher being oneself involved in experimentation. (2) A professional needs to be connected to the research in the disciplines relevant to his work and (3) (s)he has an important role in transmitting professional experience to others, and contributing to the professional field of expertise.

In thinking about and working with these ideas of Lievegoed's and Germans's, we have stretched and changed them a bit in order to make them fit better into current theories. What we have mainly done is to add the learning experiences to it. Take the first element; it is not only the working in practice, but also the learning from it: experiential learning. This includes not only learning from experience, but also making the outcomes of this learning explicit. Secondly, it is not only the being connected with research or being involved in research, but also the learning from research. Therefore, we have redefined the second step into three ways of learning explicitly: critical learning, inquiry learning, and theoretical learning (see below). Finally, it is not only the teaching of others that is important, but it is more: helping the profession develop, and by doing so learning oneself. This can be done through teaching, but also through writing books and articles, coaching, tutoring, lecturing at conferences, developing tools for others, being involved in discussions with other professions, etc. This contribution to the outside world can, in our view, also be at the team or organisational level: contributing to team learning or to organisational learning.

A learning professional is thus (see Figure 1):

(1) elaborating on his or her work-competencies by learning from and in practice (elaboration)

(2) expanding his theoretical knowledge and insights by learning explicitly from and in research (expansion)

(3) externalising his practical and theoretical insights, which means contributing to the development of the profession (externalisation) and / or to team and organisational learning. 


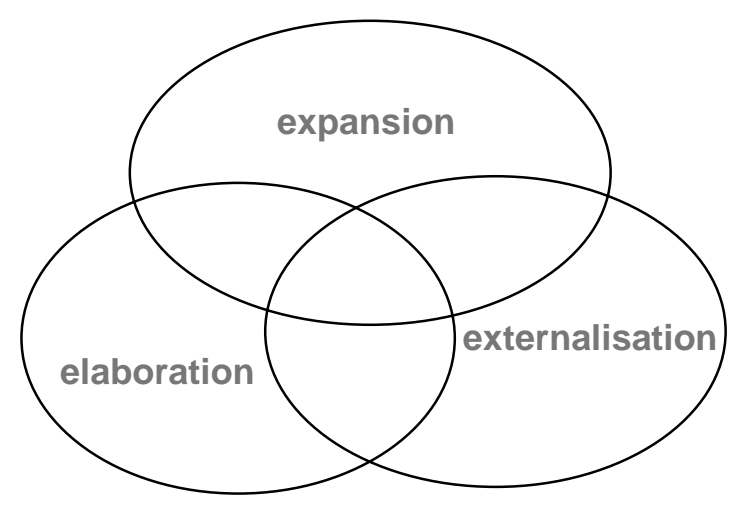

Figure 1: professional learning of learning professionals

Then, what is learning?

These three ways of being a learning professional will be discussed in more detail in the sections that follow. Let us first define learning (see Bolhuis \& Simons, (1999) for the argumentation)

Learning, in our view, refers to implicit or explicit mental and / or overt activities and processes leading to changes in knowledge, skills or attitudes or the ability to learn of individuals, groups, or organisations. These can under certain conditions also lead to changes in work processes or work outcomes of individuals, groups, or organisations.

\section{A few remarks:}

This definition starts with the acknowledgement that learning can be both implicit and explicit. While explicit learning has for a long time been the focus of attention, it becomes increasingly clear that a large part of learning is not so conscious, let alone planned or directed. Professionals learn from and in the context of their daily work. So, in talking about the learning professional, the implicit learning processes are of great relevance.

Next, we argue that learning comprises both mental and overt activities and / or processes, at the group, team, or organisational level. This distinction between activities and processes comes from Willems (1987). He convincingly argued that learning is sometimes organised (by persons themselves or by outsiders), and sometimes not at all. Then, it is "just happening as a side product of working, playing or problem solving". From 
the changes we notice, we can only afterwards conclude that these learning processes must have taken place.

Sometimes, learning can lead to changes in work processes and outcomes. Outcomes of learning can be knowledge, skills, or attitudes, but also the ability to learn can be an important result of learning.

All of this can occur at three levels: individual, team, and organisation. We want to emphasise the differences between these three levels. Team learning (or collective learning) is not the same as effectively organised learning processes of a group of individuals. Collective learning has its own characteristics and value in the light of organisational change.

\section{Distinguishing learning, development, and change}

In talking about professionalisation, it is not only learning that is relevant, but also development and change. So, for the sake of a transparent discussion, we will define both of them.

When the focus is on long term learning processes (mostly implicit), we can also call this learning "development". When the focus is on changes in work processes or work outcomes, the term "change" may be preferred. Because we have defined learning at three levels, there can thus also be group development and change, and organisational development and change. We thus use the term learning in a broad sense encompassing development and change. In a more restricted sense, learning focuses on changes in skills, knowledge, attitudes, and learning abilities. Table 1 summarises these levels of learning on the one hand, and differences of learning, development, and change on the other. The same is pictured in figure 2.

Table 1 The various ways and levels of learning and their outcomes (within the cells).

\begin{tabular}{llll}
\hline $\begin{array}{l}\text { Levels of learning } \\
\begin{array}{l}\text { Ways of learning } \\
\text { (broad sense) }\end{array}\end{array}$ & individual & team & organisation \\
\hline $\begin{array}{l}\text { Learning (restricted } \\
\text { sense) }\end{array}$ & $\begin{array}{l}\text { Skills, knowledge, } \\
\text { attitudes, learning } \\
\text { abilities of individual }\end{array}$ & $\begin{array}{l}\text { Skills, knowledge, } \\
\text { attitudes, learning } \\
\text { abilities of group }\end{array}$ & $\begin{array}{l}\text { Skills, knowledge, } \\
\text { attitudes, learning } \\
\text { abilities of } \\
\text { organisation }\end{array}$ \\
development & $\begin{array}{l}\text { long term skills, } \\
\text { knowledge, } \\
\text { attitudes, learning } \\
\text { abilities of individual }\end{array}$ & $\begin{array}{l}\text { long term skills, } \\
\text { knowledge, } \\
\text { attitudes, learning } \\
\text { abilities of group }\end{array}$ & $\begin{array}{l}\text { long term skills, } \\
\text { knowledge, } \\
\text { attitudes, learning } \\
\text { abilities of } \\
\text { organisation }\end{array}$ \\
& Work processes or & Work processes or & Work processes or \\
\hline
\end{tabular}




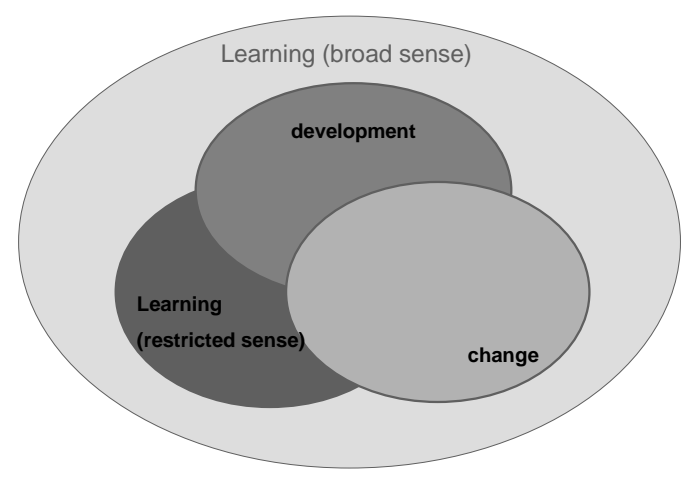

Figure 2: The various ways of learning and their interrelationships

Now that we have defined learning professionals, the three ways to learn (elaboration, expansion and externalisation) will be discussed in more detail.

\section{ELABORATION}

In our view, one important characteristic of a professional is that (s)he is working in practice, and is learning implicitly from and in that practice. We believe however, that this is not enough, but that it is important for professionals to become aware of the outcomes of their implicit learning. Why is this so?

Mini-case: Anna, aged 44, scientific degree, H R-manager

Anna impresses people with her enormous body of knowledge. There seems to be no book she hasn't read, and no theory she doesn't know about. In being confronted with a problem or assignment (in her line of work, as well as outside), almost always the first step she takes is 'researching'- what is the best model to fit this problem and where can I find directions that will lead me to a well-founded solution. In choosing her 'right'solutions, she is very strict; no compromises, she follows the idea to the end. So, although she is very concerned about the usability of ideas (they may not be too scientific), at the same 
time huge gaps between her knowledge-world and her real working-environment can become apparent. Correction or feedback by colleagues on these issues do not often occur, because of her robust nature and self-confidence, and the knowledge that she will always have convincing arguments as to the reason to act this way.

This case shows that, although putting learning-effort into expansion, there is still room for improvement. Anna mainly focuses her energy on theoretical learning, and leaves her critical learning untouched. Researching more into her values and norms, she would come to realise that her desire to work 'strictly' within one model conflicts with her desire to stay practical.

\section{Why should professionals become aware of implicit learning?}

Of late, it has (again) become increasingly clear that there are many implicit ways of learning (Bolhuis \& Simons, 1999; Doornbos \& Krak, 2001; Eraut, 2000). Here, we call this experiential learning. Both the processes and the outcomes of learning can be implicit or explicit to the learner (as well as to outsiders), resulting in four possibilities of awareness of processes and outcomes. Table 2 presents examples of all four. When learning processes are implicit, people do not realise that the activities they are undertaking or processes they are involved in, can or will lead to changes in knowledge, skills, attitudes, and / or learning ability. Awareness of learning processes (thus explicit learning processes) can arise before, during, or after the activities and processes. Sometimes, this awareness does not arise at all. When learning outcomes are implicit, people do not realise what they (have) learn(ed) during activities such as working, playing, or problem solving. Awareness of learning outcomes can also arise before, during, or after the activities or processes mentioned. And again, sometimes it does not arise at all. In that case, learning remains fully implicit.

Table 2: Examples of implicit and explicit learning processes and outcomes

\begin{tabular}{|c|c|c|}
\hline $\begin{array}{l}\text { Outcomes } \\
\text { Processes }\end{array}$ & Implicit & Explicit \\
\hline Implicit & $\begin{array}{l}\text { II: } \\
\text { A person does not know how } \\
\text { s/he learned to recognise visual } \\
\text { expressions and (s)he is not } \\
\text { aware that (s)he can do it }\end{array}$ & $\begin{array}{l}\text { IE: } \\
\text { a person knows that (s)he is } \\
\text { able to recognise emotions in a } \\
\text { face, but does not know how } \\
\text { (s)he has learned this }\end{array}$ \\
\hline
\end{tabular}


Explicit El

A person tries to learn to ride a bicycle, but does not know that (s)he is already able to do it
EE:

A person intentionally learns to drive a car, and knows that (s)he can do it.

Research shows (see for example Eraut (1998), Doornbos \& Krak (2001)) that many work-related learning processes as well as learning outcomes remain implicit. This becomes clear when people try to talk about their jobrelated learning. When Doornbos and Krak (o.c.) interviewed police officers about their work-related learning, they reported hardly any learning outcomes or learning processes. They discovered, however, that just asking them about learning was not the right approach. The word 'learning' puts people into the wrong mode: they start looking for courses they attended, books they read, coaching they received, and so on. Only when the word 'learning' was not used, and instead they were asked about changes in competencies (see next paragraph), people started to realise that they had learned a lot in and from their work. By focusing on concrete changes in work processes or outcomes, they could become aware of their learning processes. When realising what they had learned, they started to talk about how they had learned. The study showed that police officers learned many new competencies at work, ranging from new social competencies to juridical, ethical, and self-regulatory competencies. Most of these were acquired through implicit ways of learning. They were not aware of the learning, and did not even call it learning. Most of their learning processes were combinations of experiential learning, with some kind of support from colleagues. These could hardly be called coaches, however, because they were merely imitated, merely gave some feedback, or hints. Self-directed learning and guided forms of learning were almost non-existent. Instead, there was a lot of (implicit) learning with and from colleagues. Sometimes, learning started implicitly and became somewhat more explicit after a while. In other cases, learning started explicitly, but acquired a much more implicit form after a period of time.

Experiences in these studies as well as in advisory work in organisations show that there are good reasons for professionals (as well as other workers) to develop a greater awareness of learning processes and outcomes. First, when people realise what they have learned implicitly, they will develop a sense of pride, and a shift in their mindset: from learning-isonly-for-the-IQ-smart to learning-can-take-place-every-moment-in-my-work (Claxton, 1999). "Gee! I did not know that this job gives me so many opportunities to learn" or "I thought I wasn't such an egghead, but I have learned quite a lot in such a short time, and not only by being lectured at or by reading things". In our experience, it is important to start by focussing on what has been learned, not on what is lacking. 
A second reason to create an awareness of learning processes and outcomes lies in the fact that people can only share the outcomes of learning when they realise them.

And third, how can people improve their ways of learning when they do not know that, what, and how they are learning?

Hypothesis 1: Based on this, we have developed the following hypothesis: Making implicit learning results more explicit

(1) leads to job-related pride

(2) makes outcomes of learning shareable

(3) makes it possible to reflect on implicit ways of learning.

Another hypothesis that we are proposing relates to a willingness towards more explicit forms of learning (learning in more conscious ways).

We believe that more explicit forms of learning presuppose a certain awareness of previous learning processes and outcomes. When people realise that they are learning all the time and how, they will also start to realise, as demonstrated by our experiences, that certain things are not learnt implicitly and automatically, and that certain outcomes will only be realised when there is a more explicit (self-)regulation and direction.

Hypothesis 2:

Therefore our second hypothesis is:

Becoming aware of implicit learning outcomes, and the processes leading to them, leads to an increased willingness towards more explicit forms of learning.

In the next paragraph, we will first discuss ways to make implicit learning outcomes and processes explicit. In addition, we will discuss some of its potential dangers. Next, we will return to the more explicit forms of learning.

How can one become aware of one's implicit learning outcomes and processes?

Because such a huge percentage of our learning takes place implicitly (Simons, van der Linden, \& Duffy, 2000), we are intrigued by the idea of improving implicit learning. In studying experiential learning and in our consultancy practice, we have been exploring how to act on implicit learning outcomes (and consequently on their learning processes).

We have found the following issues:

First, it is important to realise that it is neither possible nor desirable to make all implicit learning outcomes and processes explicit. Moreover, sometimes it is better not to make implicit learning explicit. As Nonaka and his colleagues (Von Krogh, Ichijo, \& Nonaka, 2000) have demonstrated, there can be an implicit kind of exchange. And it is within informal activities and settings, and 
without explicitness, that people develop a feeling of shared competencies (Nonaka, Reinmoeller, \& Senoo, 1998).

When one does want to make learning outcomes and processes explicit, there are a couple of possibilities, and thus a couple of choices to make. The first choice is between reflection-in-action and reflection-on-action. In action our implicit competencies are, although not conscious to ourselves, of course visible to others. By observing people in action, a trained observer can infer these underlying competencies. By using pre- and post-action interviews, for example, people can learn to reflect-in-action, become aware of their implicit competencies, and reflect on their knowledge, skills, and attitudes themselves. In our experience, reflective practicums such as described by Schön (1987) can be a very powerful methodology. For this purpose, Klarus (1998) devised and studied an effective method consisting of a combination of pre- and post-action interviews with observations.

Reflection on action is probably less accurate, but yet very informative. For this, you can either ask others to reflect on your learning, or do it yourself. Clients or colleagues may often have a very good idea of the specific competencies they encounter in interactions with the person they want to help become aware of their implicit learning. One can just ask clients for feedback: "What, in your experience, is my specific way of working?" Besides this, three hundred and sixty degree feedback methods can be a powerful tool. It is probably more feasible, however, to use reflective methods (both individual and collective ones). Then we help people to reflect on the outcomes of their learning. We will talk in greater detail about these methods in the next paragraph. Let us first give a short recapitulation.

So, there are six ways of acting on implicit learning outcomes (see Figure 3):

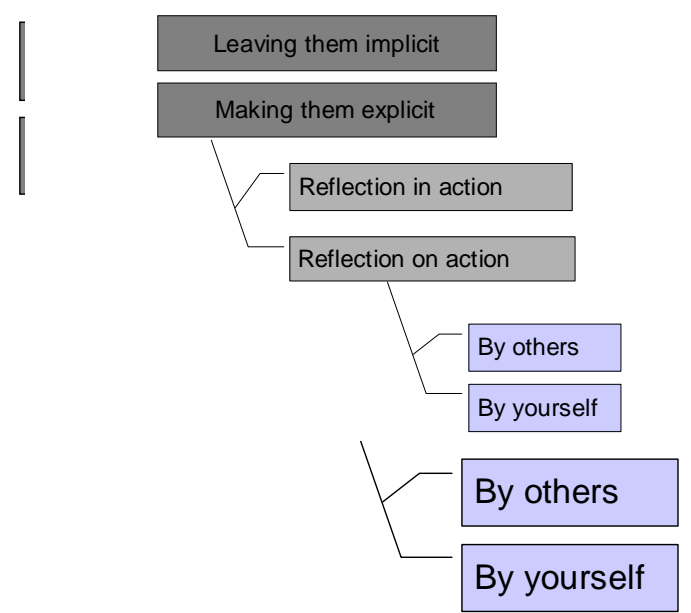


Figure 3: six ways of acting on implicit learning outcomes

\section{Self-reflection}

There are different methods that can be used to make learning outcomes explicit. Because they can add so much to professionalisation, and are not yet widely known, we will here describe some of them.

The first technique for making learning outcomes explicit through individual reflection came from Eraut (1998) and his colleagues. Instead of directly asking for learning outcomes, they asked (semi-)professionals (in their study: policemen and nurses) what had changed in their work. "In what ways is your current work different from one, two or five years ago?", "What does this tell you about what you know now and are now able to do that you were not able to then?" Another technique used is asking people to describe an ideal professional or worker. For example: "How does an ideal train conductor or an ideal human resource manager do his work?" In our experience, people have quite concrete ideal models. The next question can be "In what respect are you yourself already an ideal worker / professional?" Almost automatically, this makes learning outcomes and differences between ideal and practice explicit. And sometimes it leads to on the spot discoveries of disconnections between current ways of working and ideals, and thus to new learning opportunities. For example, we met a human resource manager describing the ideal HR-manager as someone who is constantly, informally, networking with all the line managers in the organisation. On the spot, he discovered that he himself was not practicing this at all. So, asking people to reflect on the differences between their image of an ideal practitioner and their own explicit and implicit competencies may help them become aware of learning outcomes reached thus far and their needs for a more explicit manner of learning afterwards. A third technique often used is the critical incidents method. People try to think of practical situations that were critical. From there, they start thinking of the underlying competencies. This technique resembles the 'Pretty good practices' approach described by Marsick (2001), in which people talk about examples of situations in which they performed pretty well. Marsick notes that it is important not to ask for 'best practices', because we then put too much pressure on people to excel. In our experience, we found that it is even important to avoid talking about failures altogether, and focus specifically on positive incidents. By positive critical incidents or pretty good practices, there is a greater willingness, and there are less 'defence mechanisms', to do some 'research' into details of the learning outcomes and their processes. Also related to this is the 'Story telling'-technique, where people tell anecdotes and stories taken from their practices. The difference here is in the 'story telling mindset', which triggers a certain amount of detail in describing circumstances and events from a certain distance (talking about yourself in the third person). 
Yet another technique, described by Marsick (2001) is 'Walking in the shoes of the client'. People are asked to adopt the perspective of one of their clients, and look at their own competencies through the eyes of the client. A final example of a technique described by Marsick is the 'Multiple intelligences approach'. In this approach, people try to use pictures, drawings, metaphors, movements, etc. to make clear to themselves what they have learned implicitly.

Many other techniques could be thought of. To name a few more: teaching others, looking into the future, working in heterogeneous groups, and thinking of changes and improvements.

In these examples, we can easily recognise the connection to the other two fields of professionalisation. Teaching others is, as we will see later on a way to externalise, but in teaching others we do learn a lot about our implicit learning outcomes, and in the thinking of changes and improvements, we are quite often inspired by models and articles of well-known thinkers in our fields. In these concepts and ideas lies the overlap with 'expansion'.

A common underlying general feature of all of these methods is that they start from concrete situations or experiences, and go from there to learning outcomes and competencies.

Hypothesis 3:

So a third hypothesis is:

Professionals and other workers need to think of concrete situations and experiences in order to become aware of their implicit learning outcomes.

\section{Is it always good to make implicit learning explicit?}

From the previous discussions, one might have gained the impression that we want professionals to learn in more explicit ways, both with reference to the outcomes, and to the processes of learning. We call this 'educationalising'. This is, however, contrary to our intention.

Educationalising, meaning replacing implicit learning with explicit learning, is often a mistake. It is trying to pre-plan and pre-organise learning where it had better occur spontaneously in the context of work. In our view, it can be a mistake for several reasons:

- a large part of the existing work-related learning is (as we mentioned before) implicit;

- often, people enjoy finding new solutions, and like to start new actions (and so learn implicitly) in their work, but resent learning in more explicit ways.

- educationalising may focus people's attention too much on learning instead of on working. 
Moreover, the possibility of ruining people's motivation is quite real. So, before educationalising, we suggest to pose the following three questions:

(1) What are the consequences of educationalising specific working environments?

(2) What is gained by replacing implicit learning with more explicit learning?

(3) Can we reorganise working environments to increase the chances of implicit learning?

In many instances, we think it better to find ways to help people and their managers to reorganise work in such a way that the opportunities for implicit learning increase.

\section{Increasing implicit learning without making it explicit}

This brings us to the following questions: Is it possible to (re)organise workplaces without making learning more explicit, and to improve the opportunities for implicit learning? How can we do this? Based on the studies of Onstenk (1997) and Kwakman (1999), we think it is possible by focussing on six features of work processes and work environments, being:

(1) variation

(2) responsibilities

(3) feedback

(4) reflection

(5) innovation / experimentation and

(6) vision building.

These six can be organised by managers (giving time for reflection, organising feedback, giving autonomy, planning innovation and experimentation, and so on), but they can also be organised by the people themselves. They can try to solicit feedback, reserve time for reflection, look for variation, be open to innovation, etc. All of these features of working environments can be organised individually as well as in collaboration with others: with colleagues, coaches, managers, and clients. Each of these categories of actors may introduce different perspectives and contributions to implicit learning. Table 3 summarises the possibilities.

Concluding this section, we propose the following hypotheses:

Hypothesis $4 a$

Before trying to educationalise working situations, first try to reorganise them in such a way that implicit learning is given better chances.

\section{Hypothesis $4 b$}

Implicit learning increases if working environments are organised in such a way that instances of variation, responsibility, feedback, reflection, vision building, and innovation increase. This should be done in collaboration with the five categories of actors mentioned in Table 3.

\section{Hypothesis $4 \mathrm{c}$}


Reorganising work from the perspective of implicit learning can improve (implicit as well as explicit) learning results.

\section{EXPANSION}

Although so far we have been focussing on the advantages of implicit learning processes, it seems clear that in some cases, implicit learning (processes) will not be enough. For instance, when a coherent system of new concepts has to be learned; when there are security risks involved; when intensive and guided practice of skills is needed; or when people have to look critically at their work or life. In those cases, more explicit learning processes are needed. Sometimes, implicit learning is too inefficient or not effective enough. For some kinds of learning, conscious attention to learning itself may be needed. Sometimes, implicit learning is just too difficult or too time-consuming. It is then more effective or more efficient to use explicit learning. Parts of these will take place off the job, in training courses, or in educational institutes with special responsibilities for learning. Other parts can, it is our conviction, be organised on or near the job (on the job training, coaching, mentoring, etc.). Moreover, people can also organise these more explicit ways of learning on their own, both on and off the job: self-directed learning.

Trying to improve learning on the job by making learning more explicit can involve: formulating learning goals, planning learning activities and strategies, testing learning results, monitoring learning, judging and rewarding learning and / or placing learning processes and learning outcomes at the centre of attention

This can be done by professionals, the workers themselves, or by others (teachers, coaches, managers, books, computers).

\section{Mini-case: Robert Martin, age 37, management consultant}

Robert Martin strikes one as a creative person. He has been a consultant ever since he left the university, and has published three books and several articles. Behind his impressive résumé, you would expect a man of wide reading. But quite the opposite is true. He gazes at you whenever you mention a theory, name, or title of related literature. He isn't interested in someone else's ideas, he rather elaborates on theories of his own. By reflecting on his professional learning, he characterises his own learning as trial and error, immediately putting ideas to practice, and seeing what happens. Whatever he has read is only in order to support his own thinking, and will take place during the writing of a new book. His ambitions do not regard becoming a senior consultant. He would rather become well known by his writings. 
This case made us realise once more that learning could not be cyclic. Whatever expansion Robert Martin uses always follows his externalisations and is instrumental to it.

\section{Explicit learning is not so obvious}

The studies of learning on the job by Doornbos and Krak, and Eraut mentioned above, all show that, compared to the occurrence of implicit learning, only a few people tend to organise explicit learning themselves. This probably has to do with the emotional states related to the occurrence of explicit learning. One needs some confidence before getting into (implicit) learning in the first place, and one needs some curiosity in order to be motivated to get into explicit learning (even if it concerns on the job learning). When learning explicitly, one's confidence in one's own, thus far implicit, theories and competencies will increase. Moreover, learning explicitly can even create increased curiosity: the more one knows, the more one wants to know.

\section{Three ways of learning explicitly}

We tend to distinguish three ways of learning explicitly: Theoretical learning, Inquiry learning, and Critical learning (Bolhuis, 1995). In theoretical learning, the learner (or trainer) decides to learn new concepts and ideas, and to connect pre-existing concepts and ideas to those of others or to existing theories and research outcomes from the profession or discipline. This is a way of learning to focus on concepts, ideas, research outcomes, theories as developed by others, sometimes in scientific research, sometimes in thinking based on experience. In essence, it is connecting ones' own concepts, ideas, theories, and research outcomes to those of others inside and outside the profession. One does this, for instance, through reading books, attending conferences, being involved in discussions, and by comparisons.

Inquiry learning is a form of (action) research: learners (and or trainers) decide to find out whether hypotheses arising from experiential learning remain valid under varying conditions, or can be tested (semi-)systematically on the job, or in more scientific research. Hakkarainen et al. (2000) describe a useful inquiry-learning model for educational situations, which can also be used on the job.

In critical learning, people look critically at their norms and values. It concerns questions such as "Are we walking the talk?", "Don't we have to adjust our way of working or learning in a more fundamental way?", "Is our way of working still in line with our norms and values?", etc. Although this form of expansion is closely related to elaboration, for this purpose our learning should already be explicit in order to be an element of research. Besides this, the central question is always in part one of theoretical ideas 
and concepts: are the ones we have chosen (have espoused) in harmony with what we show (in our actions)?

Hypothesis 5:

The hypothesis underlying this section is the following:

Explicit individual learning will occur and will be needed when people want to

(1) expand and test their action theories (inquiry learning),

(2) compare these with other theories (theoretical learning) and

(3) check whether they are walking the talk or are still working in line with fundamental assumptions (critical learning)

\section{EXTERNALISATION}

The third part of our learning model, externalisation, refers to the need we see for professionals to connect their learning to concrete and public milestones. These milestones can be in the profession (publications, lectures, workshops, teaching activities, etc) or in the workplace, both at the team level (plan for group actions; contributions to team learning), and the organisational level (contributions to company policies or to organisational learning). Common in these milestones is that they are concrete, and related to (learning-) activities of other people. Moreover, these milestones can be made visible and connected to a date and a place. For instance, "I will write an article in that journal before the end of this year", "I will make a checklist for my organisation before Christmas, and publish it on the company web" or "I feel the need to reformulate our vision and collective ambitions (due to new insights I want to share). Let's plan a date shortly". Concrete milestones make the outcomes of explicit as well as implicit learning visible, and easy to share and plan. Milestones can bring the necessary challenge that helps the learner to keep up motivation to continue and to learn, and to put personal learning outcomes in relation to the learning and working of other people. Professional colleagues and team members can co-profit from one's learning, and the learner has something to look forward to. The milestone can provide an extra form of reward when achieved. It is exciting to see people use what you have learned and developed. It is rewarding to see that one's article is accepted for publication in a journal, etc. But most of all, it is the learner who, in searching for the right words, or explicating ideas necessary for teaching others or making concrete applications, again profits from learning.

\section{Mini-case: Bereta, age 35, university teacher}

Bereta is a friendly and sociable type of person, committed to both his work as a researcher-teacher and "his students". He is 
a quick learner. In order to become acquainted with for example a new computer program, or a new way of teaching, he just sits down and observes. You don't even realise he is learning, until the time he will come back to you and asks a detailed question. The next thing you'll notice is his striving for perfection. The results show. His students like him, and reward his attempts to be the 'best teacher'. His perfectionism hides the fact that he isn't really into expansion, until he changes profession, and becomes an advisor for personnel and finance. Although this was an old dream come true, he wasn't at all prepared, and didn't realise he didn't have to sit back and wait for his 'education'. The possibility of actively searching for information on the net and in books, asking for coaching and so on, didn't cross his mind.

Bereta's learning power lies clearly in elaboration. And although his profession is teaching - this shouldn't be confused with externalisation. Teaching is his primary process, not a way to externalise his thinking and insights on teaching. In his switch to another job, it would be very helpful if he could apply his learning power in expanding and becoming a professional on his own strength.

Hypothesis 6:

The hypothesis we propose:

Determining externalised milestones helps people to intensify and sustain their implicit and explicit learning on and near the job.

\section{THE COMPLETE MODEL OF ELABORATION, EXPANSION AND EXTERNALISATION}

Figure 4 presents the full model in which all of the ways of learning are being distinguished. 


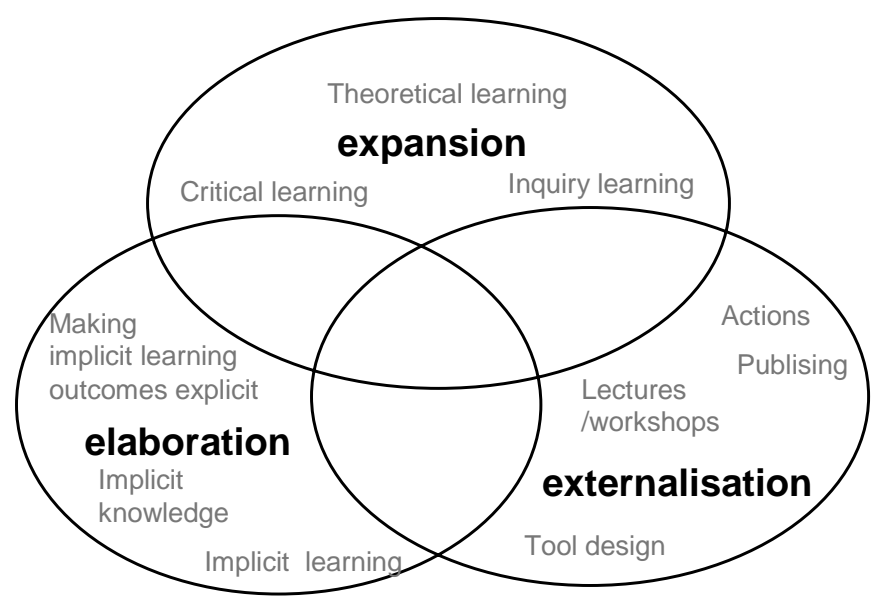

Figure4: All forms of learning together in one view

\section{THE ROLE OF EMOTION IN LEARNING AND PROFESSIONALISATION}

Learning is not only about cognition, although most of the learning-models and theories are. As learning becomes more complex, and more challenging, more emotions come into play.

We believe that a feeling of safety is a necessary and fundamental emotion involved in all kinds of learning. Therefore, we have placed this at the heart of the model. It is not something static, but evolves from the 'family of emotions' being interest / anxiety / excitement (Claxton, 1999). The interplay between these basic components causes a readiness for learning, and a 'resilience' as Claxton calls it.

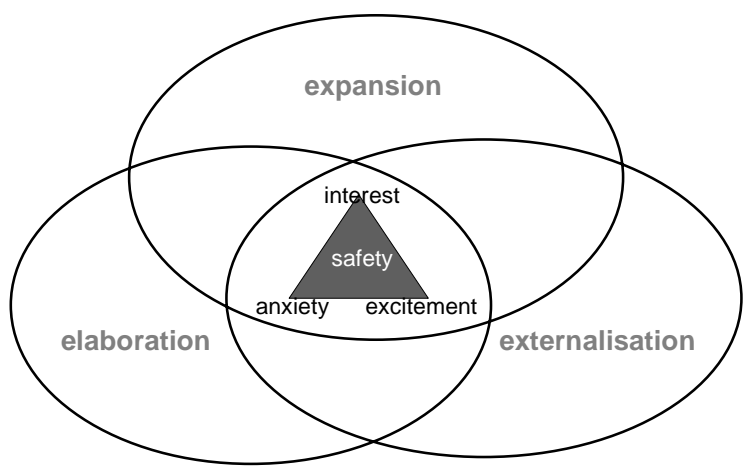


Figure 5: the basic family of emotions related to learning

Elaborating on learning, as we do in our theory of the learning professional, we detect more specific emotions linking the different stages: elaboration, expansion, and externalisation.

In the previous paragraphs, we have already implicitly mentioned several emotional states, such as pride, confidence, and curiosity, which we considered to be important in themselves.

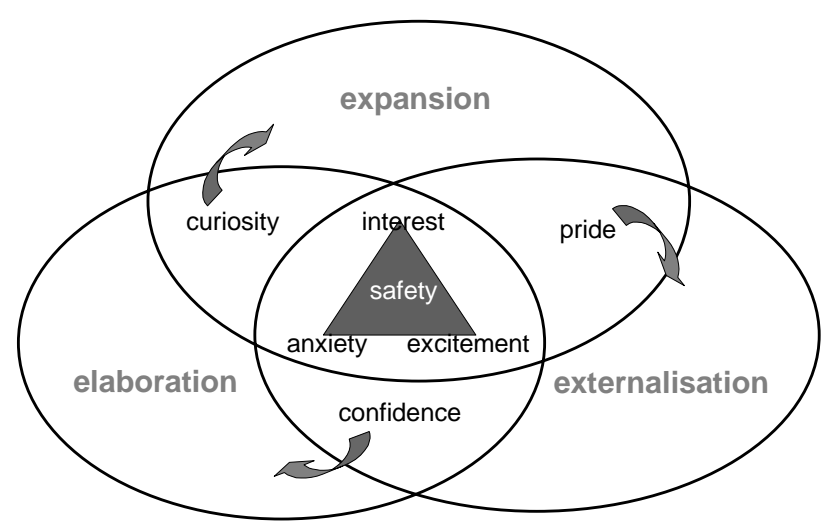

Figure 6: the family of emotions related to elaboration, expansion, and externalisation

In addition, we think that there are reciprocal relations between the emotional states and learning, meaning that the pre-existence of the emotion makes the kind of learning more probable, and that the emotional state increases after learning has been successful. Take curiosity, for example. This is needed for explicit learning, and by expanding on your knowledge, insights, and skills, the level of curiosity may increase. Equally, having confidence increases the willingness to make implicit learning explicit, and having done this may increase one's confidence.

Finally, each stage has its own emotional outcome. Elaboration leads to a feeling of competence, expansion leads to a feeling of mastery, and externalisation leads to a feeling of satisfaction. 


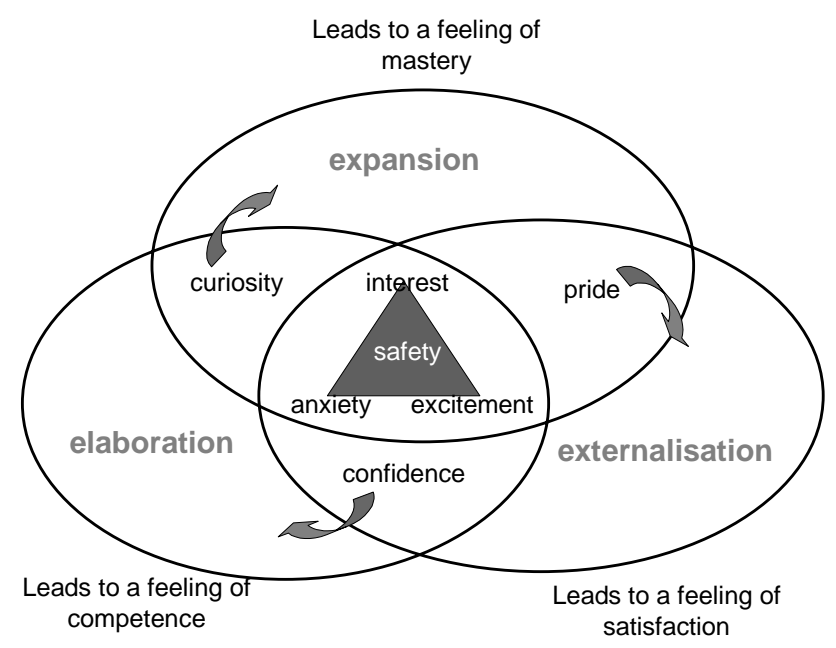

Figure 7: the emotional outcomes related to the three stages

The two hypotheses underlying this section are:

Hypothesis 7: There are reciprocal relations between emotional states and ways of learning:

(1) elaboration, and confidence and curiosity

(2) expansion, and curiosity and pride

(3) externalisation, and pride and confidence

(4) All three ways of learning, and feelings of safety.

\section{Hypothesis 8:}

Each stage has its own emotional outcome.

Elaboration leads to a feeling of competence, expansion leads to a feeling of mastery, and externalisation leads to a feeling of satisfaction.

\section{COLLECTIVE LEARNING}

Thus far, we have treated learning as if occurring with individual professionals only. But collective learning is gaining importance. The accelerating developments within our society make it necessary, but not enough, to have excellent professionals in a work force. More and more, these professionals need to be able to work together in solving problems and in innovating more accurately and quickly. 
So, more and more professionals are working in teams, both interdisciplinary or monodisciplinary. The consequence of this, namely that professionals should also learn collectively, has so far not been much discussed. In our view, future professional learning needs to be broadened to include collective learning. Two forms of collective learning are to be distinguished: organisation-related and profession-related collective leaning.

Organisation-related collective learning refers to processes and intended outcomes of learning of a work team or an organisation. Teams of professionals or teams including professionals decide to collaborate in learning, focusing on common learning activities and processes, or on common outcomes. 'Communities of practice' (Wenger, 1998), sharing a common interest in the organisation, learn in and from their work and share this. This kind of collective learning has been described more fully elsewhere (Simons \& Ruijters, 2001). There, we distinguished collective elaboration, collective expansion, and collective externalisation, which lead to different types of collective outcomes, for example: balanced primary processes, collective quality standards, gained and shared new insights, and collective visions, innovations, and action plans for the team and / or organisation.

Profession-related collective learning consists of professionals, working in different organisations, but sharing the same profession, and deciding to learn together from their different practices. They don't have a common interest in one organisation. They may even be competing for the same clients. Their common interest is in learning. Therefore, we call these 'communities of learners' and not 'communities of practice'. Collective outcomes can be partly the same as those of communities of practice, but in addition, collective professional outcomes relate to contributions to the professional field publications, lectures, tools, etc..

\section{Conclusion}

Our new model of professional learning defines professionalism in a dynamic way, as continuously working on vision, methodology, tools and techniques, and the alignment between these three components by:

(1) elaborating on his or her work-competences

(2) expanding his or her theoretical knowledge and insights

(3) externalising his or her practical and theoretical insights, which means contributing to the development of the profession and / or to team and organisational learning

We realise that this, including the various ways to learn at these three stages, is in a sense a normative model of professionalism. It specifies that professionals should be continuously involved in different kinds of learning, and how they can organise this. We argue that every kind of learning, be it by elaboration, expansion, or externalisation, has its own value for lifelong learning of a professional. 
We also argue that confidence, curiosity, and pride are emotions bridging these three stages. For example, one needs to feel curious in order to expand - and expansion leads at a certain point to pride, which forms the basis of externalising, and so on. The different stages of learning add to the feelings of competence, mastery, and satisfaction.

Finally we indicated that at present a model of professional learning cannot be one of just individual learning. Collective learning needs to be a part of it. We find the three-stage model of professional learning equally useful on a collective level, but refrained from getting into this here, given the limited length of the present article and our previously mentioned publication.

Although parts of the model are based on empirical research, the hypotheses still await further empirical testing. We hope that researchers and practitioners will take up the challenge to test them, and that we ourselves will be able to do that research in the years to come. 


\section{REFERENCES}

Bolhuis, S. (1995). Leren en veranderen bij volwassenen. Een nieuwe benadering. Bussum: Coutinho.

Bolhuis, S. M., \& Simons, P. R. J. (1999). Leren en werken. Deventer: Kluwer.

Brown, J. S., \& Duguid, P. (2000). The social life of information. Boston: Harvard Business School Press

Brown, J. S., Collins, A., \& Duguid, P. (1989). Situated cognition and the culture of learning. Educational Researcher, 18(1), 32-42.

Claxton, G. (1999). Wise up: the challenge of life long learning. London: Bloombury.

Doornbos, A. J., \& Krak, A. J. A. (2001). Learning processes and outcomes at the workplace: a qualitative study. Paper presented at the Conference on HRD Research and Practice Across Europe, Enschede.

Engeström, Y. (1999).Innovative learning in work teams. In Y. Engeström, R. Miettinen, \& R. Punamaki (Eds.), Perspectives on activity theory (pp. 377404). Cambridge: University Press.

Eraut, M. R. (1998). Development of knowledge and skills in employment. Brighton: University of Sussex Institute of Education, Education Development Building

Eraut, M. R. (2000). Non-formal leanring and tacit knowledge in professional work. British Journal of Educational Psychology, 70, 113-136.

Germans, J. (1990). Spelen met modellen. Unpublished PHD, Tilburg University, Tilburg.

Hakkarainen, K., Ilomaki, L., Lipponen, L., Muukkonen, H., Rahikainen, M., Tuominen, T., Lakkala, M., \& Lehtinen, E. (2000). Students' skills and practices of using ICT: results of a national assessment in Finland. Computers and Education, 34(2), 103-117.

Klarus, R. (1998). Competenties erkennen. Een studie naar modellen en procedures voor leerwegonafhankelijke beoordeling van beroepscompetenties., Katholieke Universiteit Nijmegen, Velp.

Kwakman, C. H. E. (1999). Leren van docenten tijdens de beroepsloopbaan. Nijmegen: PHD, Katholieke Universiteit Nijmegen

Lehtinen, E. (2001, July 15-20). Organizational learning and networked expertise. Paper presented at the workshop Changes in the workplace and their implications for education, Regensburg.

Lievegoed, B. C. J. (1977). Organisaties in ontwikkeling, zicht op de toekomst. Rotterdam: Lemniscaat.

Marsick, V. (2001). Informal Strategic Learning in the Workplace. Paper presented at the Second Conference on HRD Research and Practive Across Europe, Enschede, The Netherlands.

Nonaka, I., Reinmoeller, P., \& Senoo, D. (1998). The 'ART' of knowledge: Systems to capitalize on market knowledge. European Managament Journal, 16(6), 673-684. 
Onstenk, J. H. A. M. (1997). Lerend leren werken. Brede vakbekwaamheid en de integratie van leren, werken en innoveren. Katholieke Universiteit Nijmegen, Amsterdam.

Schön, D. A. (1987). Educating the reflective practitioner: Toward a new design for teaching and learning in the professions. San Fransisco: Jossey-Bass.

Simons, P. R. J., Linden van der, J., \& Duffy, T. (2000). New learning: three ways to learn in a new balance. In P. R. J. Simons \& J. Linden van der \& T. Duffy (Eds.), New Learning (pp. 1-20). Dordrecht: Kluwer Academic Publishers.

Simons, P. R. J., \& Ruijters, M. C. P. (2001). Work related learning: elaborate, expand, externalise. In L. Nieuwenhuis (Ed.), Dynamics and stability in VET and HRD. Enschede: Twente University Press.

Thijssen, J. (1987). Bedrijfsopleidingen als werkterrein. Den Haag: Vuga.

Von Krogh, G., Ichijo, K., \& Nonaka, I. (2000). Enabling knowledge creation. Oxford: Oxford University press.

Wenger, E. (1998). Communities of practice. Cambridge: Cambridge University Press.

Willems, J. (1987). Studietaken als instructiemiddel. Unpublished PHD, Katholieke Universiteit Nijmegen, Nijmegen. 